\title{
Pepe Batres, poeta de Guatemala
}

T os literatos centroamericanos son muy poco conocidos 1 fuera de su Istmo, a menos que hayan salido de la región, siguiendo el ejemplo de Rubén Darío o Gómez Carrillo. Por eso me propongo presentar al poeta romántico Pepe Batres, y describir el ambiente en que vivió.

La primera vez que oí mencionar a José Batres fue en el año 1945 durante una visita al Palacio Nacional de Guatemala, cuando por casualidad entablé conversación con un joven, quien me regaló un periódico literario que acababa de publicar. Era poeta también, y quería lograr de su gobierno que se le señalase una asignación de papel, que en esos días sufría un severo racionamiento.

La revista reproducía varias poesías de José Batres, y las leí con interés. Más tarde conocí a una distinguida escritora del país, a quien pregunté cuál era la importancia del poeta en las letras patrias.

-Oh, Pepe Batres, - me contestó con entusiasmo, -representa perfectamente el movimiento romántico en estas tierras. Sufría como todos los poetas, y además conoció las penas de nuestras inquietudes políticas y económicas. Las supo expresar; y como un desahogo para olvidarlas, se dedicó a sus versos. ¿Ha leído Vd. sus Tradiciones festivas? -me preguntó a su vez; - son auténticamente guatemaltecas, y pintan nuestra sociedad hasta la fecha. La poesía de José Batres merece mayor fama dentro de las letras patrias y castellanas.

Pepe Batres, como cariñosamente es llamado, o José Ma- 
riano Gabriel Lorenzo Batres Montúfar, como fue bautizado, nació en la ciudad de San Salvador el 12 de enero de 1809 . Su padre era "Contador de Real Hazienda" de aquella provinca todavía española, aunque pertenecía a una distinguida familia de Santiago de los Caballeros, capital colonial llamada actualmente Antigua Guatemala. José Mariano Batres y Asturias había recibido su educación en España, y demostrado cierto talento para la poesía, don que culminaría en su ilustre hijo. Contrajo matrimonio con doña Mercedes Montúfar y Coronado, miembro de otra familia destacada de Guatemala desde el siglo XVII.

En 1822 la familia tuvo que huir de San Salvador pues el movimiento de independencia amenazó la vida de don José Mariano por ser funcionario de la Corona. Así, a los trece años Pepe se trasladó con la familia a la ciudad más conservadora de Guatemala. Su padre sirvió primero bajo Agustín de Iturbide, y cuando el emperador mexicano perdió las provincias de Centroamérica, pasó al servicio del gobierno de la nueva república istmeña con el parco sueldo de mil quinientos pesos. La familia Batres se había instalado en la Octava Calle frente al parque infantil de hoy día, y durante bastante tiempo sufrió una gran penuria.

Pepe recibió sus primeras letras en el hogar, y dos años después de llegar a Guatemala, empezó su enseñanza secundaria en la Escuela de Cadetes que dirigió su tío político, el coronel Manuel Arzú. Obtuvo el grado de subteniente de artillería antes de cumplir los dieciocho años, y casi inmediatamente partió en campaña contra El Salvador, estado de la Unión en pugna con Guatemala; tomó parte en varios combates y fue capturado en el pueblo de Mexicanos ante su ciudad natal. Así sufrió su segunda experiencia personal de las inquietudes y problemas por los que pasaba Centroamérica en aquellos tiempos, y a la vez durante esta campaña, escribió a su casa una carta en verso preludio de sus futuras poesías.1

Dos tíos suyos, don Manuel y don Juan Montúfar, y su gran amigo "Chafandín" o Miguel García Granados, compartieron su prisión. García Granados ha escrito que los herma-

1 José Arzú nos la da en las páginas 136 a 138 de su biografía Pepe Batres 
nos Montúfar tenían un buen surtido de libros, y que durante su cautiverio los leyeron todos. Pepe enseñó a Chafandín a leer los que estaban escritos en francés, mientras éste reciprocó enseñando a Pepe el inglés. La pérdida de tiempo y de talentos en las cárceles políticas de Centroamérica es tristísima, y consuela saber que estos jóvenes pudieron sacar algún provecho en estos dos años. Además de dedicarse a la lectura, pasaban el tiempo jugando al ajedrez. Pepe llegó a poderlo jugar a ciegas.

Mientras tanto las tropas federales bajo el mando del general hondureño Francisco Morazán invadieron Guatemala, y la casa de los Batres fue saqueada por la soldadesca. Pepe recobró su libertad en 1829, y permaneció algún tiempo en la población salvadoreña de Sonsonate antes de proseguir a Guatemala. En Sonsonate reconoció en manos de soldados enemigos algunas prendas familiares procedentes del saqueo, pero sin lograr nueva posesión de ellas. De regreso a Guatemala, encontró que su familia había dejado la capital por el solar: colonial de la Antigua, donde él también fijó su residencia. Describe un duro viaje entre las dos ciudades en el año 1836, en muy distintas condiciones de las actuales con los adelantos viales. Compuso sus primeros versos según las reglas durante esta época, siendo el primer ensayo Un día de campo; le siguen De repente y luego sus Décimas.

Como su familia se encontraba sin recursos, Pepe resolvió estudiar para ganarse la vida como profesional. Obtuvo el título de ingeniero topógrafo o "agrimensor" en 1835 en la Academia de Ciencias, a la edad de veinticinco años. Pepe pasó sus mejores años como universitario, cuando gozó de relativa tranquilidad. Fue un matemático experto y tuvo afición por la geometría analítica. Leyó todos los artículos científicos de

intimo (Guatemala, 1940). Otra carta en su poema El relox demuestra este talento para la epistola en verso; empieza así:

"Jueves diez-Querida Juana;

"No puedes figurarte con la pena

"que me tiene tu viaje pues a cada

"rato estoy preguntando como un ena-

"morado cuando vuelves... 
la Encyclopaedia Britannica de la época; Fernando Cruz dice en su libro Biografias de literatos nacionales:2

\begin{abstract}
Establecida de nuevo en la capital con su familia, se mantenía siempre a caza de los libros nuevos que llegaban a poder de sus amigos. Las obras de importancia estaban tan poco generalizados que Batres parecía loco de placer cuando llegó a adquirir la famosa Enciclopedia Británica. La trajo a Guatemala el eminente educador y notable literato y matemático D. Manuel Domínguez; y después de pasar a otras manos, vino a parar a las de Batres. La leyó y la estudió detenidamente y la llenó de notas marginales de las observaciones que le sugería su lectura. De tanta significación eran éstas, sobre todo en la parte relativa a su profesión, que D. Santiago Barberena, cuyos conocimientos en las ciencias exactas fueron tan notables y que después del fallecimiento de Batres compró la obra citada, decía a su hermano politico, el Sr. Arzú: Ahora por las notas marginales de la Enciclopedia he venido a conocer hasta donde llegó Pepe $\mathrm{Ba}$ tres en las matemáticas.
\end{abstract}

En esta época la venerable Universidad de San Carlos estaba clausurada, para no volver a abrir sus puertas hasta después de la derrota del general Morazán por Rafael Carrera. La Academia de Ciencias en la cual se graduó José Batres fue fundada en 1832 para sustituir a la universidad colonial, la que siendo de tendencias clericales, se encontraba en pugna con las ideas del gobierno federal; pero el único verdadero cambio fue el nombre, pues se usaron las mismas aulas y casi el mismo profesorado. El prócer don Pedro Molina Flores era presidente de la Academia, y como mentor de Pepe y profesor liberal, puede haber ejercido alguna influencia sobre el poeta. Se ha dicho que Batres enseñó en la universidad, pero las únicas lecciones que daba eran las de guitarra, a sus hermanas y las amigas de ellas. Su primer empleo profesional fue en el pueblo de Patzicía, cuyos habitantes tienen hasta la fecha la fama de ser notoriamente levantiscos; en ese lugar aún el párroco vivía en una choza, en la que se hospedó Pepe.

En el año 1837 fue nombrado ayudante del ingeniero in-

2 Guatemala, Academia Guatemalteca, 1889; pág. 169, bajo la cabecera "El poeta D. José Batres". 
glés John Baily, y lo acompañó a Nicaragua para estudiar las posibilidades de comunicar los dos océanos por medio de un canal. Baily era un ingeniero y oficial de la Real Marina inglesa que la federación de Centroamérica había contratado; llegó de Londres en 1824 en representación de la casa de Barclay, Herring, Richardson y Cía. ${ }^{3}$ En el mes de marzo, Pepe y su hermano Juan salieron con Baily para el río San Juan en la costa del Caribe, mientras reinaba una terrible epidemia de cólera desde el Canadá hasta Costa Rica. El viaje fue largo y cansado, y Pepe describe su desagrado al pasar por El Salvador que le recordó los malos tiempos vividos allí. Las cartas a su familia son excelentes, sobre todo las descripciones de la ciudad de Granada, en la cual pasó largo tiempo a su regreso; encontró que Nicaragua era muy provinciana, pero pudo obtener buena alimentación allí. A pesar de su amistad con el ingeniero Baily, le preocupaba grandemente la influencia inglesa en la costa del norte y las islas del Caribe.

Pepe tenía otra preocupación más íntima, sobre la salud de su familia durante su ausencia; pero en realidad las víctimas eran su hermano y él mismo. Juan tenía doce años en 1829, de modo que tendría veinte cuando murió de paludismo, en una anticipación de la tragedia de De Lesseps en Panamá, medio siglo después. De su viejo profesor, don Pedro Molina, que era médico de profesión, recibió una prescripción para curar sus fiebres, informes transmitidos por medio de su hermana Nela. Pepe expresó en un intenso poema escrito en versos de arte mayor, La elegía de San Juan, su inefable tristeza y odio al ambiente hostil del Caribe, que le robó a un hermano tan querido; reproducimos unas estrofas del mismo, advirtiendo la fuerza de su sufrimiento en la repetición de la primera línea como la última:

3 El emisario de los Estados Unidos, John Lloyd Stephens, narra (Incidents of Travel in Central America [New York, 1841]; 2 tomos; 1. 389) que acababa de tomar estas medidas poco tiempo antes que él mismo, de modo que aquí tenemos a las dos potencias anglosajonas disputándose el privilegio de construir el canal. Ni Stephens ni Baily mencionan a Batres en sus respectivos libros, éste quizás por su reserva británica, y aquél porque Pepe estaria ya de jefe político en Amatitlán durante su visita. 
De fieras poblado, de selvas cubierto que vieron erguidos cien siglos pasar allá en Nicaragua se extiende un desierto. $\mathrm{Su}$ historia... ninguna! su limite... el mar...

No guarda en su seno ni mieses ni flores, no viste sus valles de espléndidas galas, no danzan en ellos ni cantan amores apuestos donceles con lindas zagalas.

Sus vegas infestan salvajes desnudos cruzando sus aguas en toscos acales: caimanes feroces, voraces, membrudos, disputan con ellos sus turbios canales...

Tu nombre tenía mi amigo, mi hermano, sobre el derramaste tu odioso veneno, apenas bebiendo su aliento lozano el aliento impuro que brota tu seno.

¡Por él te maldigo! ¡Por él te saludo! Mis lágrimas guarda, maldito desierto; de prados, de mieses, de flores desnudo, de fieras poblado, de selvas cubierto.

Su regreso a Guatemala ocurrió al año exacto de la fecha de su salida. Debilitado física y espiritualmente, pudo dedicarse más a sus lecturas y escritos, porque su familia ya disponía de mejores recursos; pero a pesar de este favorable cambio de fortuna, Pepe quedó con una incurable tristeza, cifrando su único interés en sus parientes y amigos. En 1839 sirvió como "Gefe" político del distrito de Amatitlán, al sur de la capital en la zona cálida, y fue elegido diputado a la asamblea guatemalteca por el "barrio" de San Marcos en 1842. Una poesía ofrece la siguiente referencia a la Ley de Garantías proclamada por la legislatura del Estado en 1837 (fue escrita por su personaje don Pablo mientras éste se encontraba encerrado en el convento) :

Hizo un ensayo en forma de tercetos garantias llamadas individuales, y unas cuantas octavas y cuartetos contra los institutos monacales. Compuso dos bellísimos sonetos atestados de ideas liberales 
en loor del Habeas Corpus, que decía que algún día en su patria regiría.

Otro ejemplo de su saña cívica mezclada con una decepción personal se encuentra en el poema Las falsas apariencias:

El brillo de tu gloria vi empañado por los traidores que tu seno encierra, y vi escupir en tu blasón dorado, y vide hollar tu pabellón por tierra. Más de un Gobierno, más de un diputado en vez de hacerte bien te hicieron guerra y quisieron pintar ioh escarnio crudo! lagartos y colmenas en tu escudo!

Durante la campaña contra Morazán en 1840, cuando por última vez se trató de restablecer la deshecha confederación, fortificó la capital y fabricó granadas para la artillería del Estado independiente. Morazán tuvo que retirarse después de tomar la ciudad. Durante la ocupación, Pepe había buscado asilo en el consulado francés (no había legaciones allá todavía, si descartamos la misión ambulante del Sr. Stephens) a causa del desorden reinante en la capital. Recibió del nuevo presidente del Estado soberano y libre de Guatemala, Rivera Paz, una medalla por su valor. El capitán Batres Montúfar no tuvo que prestar servicio militar durante la invasión de Malespin en 1844, porque su salud se encontraba minada definitivamente; la "excepción" le fue concedida sólo seis semanas antes de su muerte.

La obra poética de José Batres Montúfar se divide en tres ramas principales: las traducciones, cuyos títulos sólo al paso mencionamos aquí ( $A$ la rosa siguiendo al poeta francés Bernard, y las odas horacianas $A$ Pirra y $A$ Leucone) ; sus piezas líricas, que consideraremos en seguida; y las Tradiciones de Guatemala escritas en octavas reales. Señalamos aquí que el nombre "tradición" fue recogida más tarde por Ricardo Palma cuando quiso evocar el período colonial del Perú, con el único cambio del apelativo nacional. Algunas piezas resisten a estas 
clasificaciones, y su verdadera fama descansa en sus Tradiciones, en el madrigal Yo pienso en ti y en la Elegía de San Juan ya citada en parte.

Desde la niñez, Pepe Batres fue un aficionado de la literatura, $\mathrm{y}$ hemos visto cómo vivía "a la caza de los libros" según Fernando Cruz. Sabía latín, francés, italiano e inglés, y leía vorazmente en esos idiomas; "la digo porque Byron la decía" exclama, y menciona a Rousseau, Voltaire y Richardsón "con acento en la sílaba final" para que salga mejor la rima. Había leído las crónicas de la conquista, las obras de Juan Ruiz, de Cervantes, y los romances españoles: "A las crónicas soy aficionado, // a las de Guatemala sobre todo", confiesa, mencionando a varios historiadores. Su poesía está cargada de alusiones, como su comparación del brinco de un protagonista con el salto de don Pedro de Alvarado y su evocación de las antiguas ciudades de Tlaxcala y Utatlán. A pesar de fuentes tan diversas, supo forjar un estilo propio; sus descripciones del paisaje de Centroamérica son típicas, y emplea figuras como "en el pecho // un volcán parecía que tuviera". Efectivamente, El volcán de agua, dedicado al soberbio cono que domina la ciudad de la Antigua es una de sus mejores piezas líricas; demuestra la invitación al pensamiento que inspira aquella montaña:

\footnotetext{
$\mathrm{Y}$ sin saciar su vista ni su mente, por estrecho sendero y escarpado baja de la montaña lentamente el sabio a sus ideas entregado; jaquel gran monumento de la tierra! tal virtud, tal poder, tal fuerza encierra
}

Suicidio nos interesa porque revela sensibilidad ante la muerte, pero sin miedo alguno. Fue compuesto antes del viaje a Nicaragua, y manifiesta su escepticismo hacia la vida; nótese como hace burla de las flaquezas humanas:

También se quita la vida

la mariposa en la llama;

buscando lo que más ama

se mata el hombre enviciado, 
y con un corsé apretado

suele matarse una dama.

Desde los dieciocho años, cuando empezamos a observar su proceso mental, Pepe Batres había demostrado fuerte disciplina personal y un carácter serio. Fue buen observador y gozó de una reflexión muy madura para esas mocedades; pero a medida que pasaban los años, sus privaciones, mediocre salud y proyectos frustrados le insinuaron la sospecha de que la vida le importaba poco. Sólo unos afectos familiares y el cariño de varias amistades le infundían el deseo de vivir, y su vocación literaria le ofreció otro refugio en contra de la vida. Algunos dicen que la muerte de su hermano Juan le quitó todo interés en la vida, y la Elegía de San Juan demuestra genuino dolor; pero vale la pena hacer constar que también enfermó de paludismo en la misma ocasión, añadiendo así un malestar muy personal a la tragedia de su alma. Después de ese malhadado viaje, Pepe Batres fue un hombre enfermo, que sufría terribles dolores físicos que acabaron de entristecer su ánimo.

EI poema $Y o$ pienso en ti fue la ocasión para revelar una pasión amorosa "con el alma prima y sangrante", y no nos extraña que su retrato verbal nos muestre un rostro melancólico, ni que su tono sea algo amargo. Parece que nutría un amor ideal que nunca supo alcanzar, o que sufría una pasión que por motivos inexplicables sólo pudo expresar por medio de la poesía. A Pepe le gustaban las mujeres, pero se burlaba de ellas. Además, su círculo de amistades era tan reducido que una verdadera pasión se habría descubierto, y no hay prueba de ningún amorío serio de su parte. A Luisa Meany o a Adela García Granados pertenece el prestigio de haber inspirado este hermoso madrigal; sus biógrafos favorecen a Adela, y en caso de ser la verdad, serían dos señoritas García Granados quienes fueran inmortalizadas por dos poetas: Adela por José Batres, y María por José Martí en La niña de Guatémala.

No importando cómo haya sido, se siente en estas líneas un anhelo afligido, un grito del alma que quiere alcanzar a algún objeto de su pasión; forman uno de los más perennes madrigales de las letras castellanas, y para apreciarlo mejor 
hay que leerlo en voz alta, y captar así su exquisito e incansable ritmo:

Yo pienso en ti, tú vives en mi mente sola, fija, sin tregua, a toda hora, aunque tal vez el rostro indiferente no deje reflejax sobre mi frente la llama que en silencio me devora.

En mi lóbrega y yerta fantasía brilla tu imagen apacible y pura, como el rayo de luz que el sol envía a través de una bóveda sombría al roto mármol de una sepultura.

Callado, inerte, en estupor profundo, mi corazón se embarga y se enajena, y allá en su centro vibra moribundo cuando entre el vano estrépito del mundo la melodía de tu nombre suena.

Sin lucha, sin afán y sin lamento sin agitarme en ciego frenesí, sin proferir un solo, un leve acento, las largas horas de la noche cuento $\mathrm{y}$ pienso en ti!

Quisiera oír Yo pienso en ti, tan lleno de ritmo, como una canción; las palabras habladas no nos comunican su completa belleza, y su verdadero medio de expresión debe ser la voz cantada. Como Pepe era aficionado a la música, es interesante esperar que algún día se encuentre alguna melodía suya para esta poesía; Aqui en mi pecho tiene música, y también nos revela un secreto:

Aquí en mi pecho oculta está mi violenta pasión; mudo a tu vista, callara temblando el corazón.

Parecida es la linda serenata dedicada por don Alejo a doña Clara en El relox, que empieza: "Duerme, i oh bella! en paz y en calma. ${ }^{4}$

4 Ramón Uriarte reproduce la letra completa de esta canción en su Galería poética centroamericana, I. 222-3 (Guatemala, La Unión, II edn., 1888, 3 tomos); 
La primera Tradición lleva por título Don Pablo; apareció en $E l$ Café, un periódico efímera que dirigió Pepe Batres durante el año 1839. El poeta empieza diciendo que piensa "daros un consejo" a la manera de Giambattista Casti, a quien imitó confesadamente; pero Pepe supo llevar el concepto más lejos y coser el estilo descuidado del abate italiano. Parece que Dionisio Alcalá Galiano, hijo del estadista don Antonio, le dio a conocer la obra de Casti y de Byron. Al principio su adaptación resultó bastante literal, pero al advertir cierta dificultad de expresión, el poeta formó su estilo personal; nos dejó así tres cuentos en verso que son a la vez hábiles y chistosos. ${ }^{5}$

El protagonista del primer cuento, don Pablo, está enamorado de Isabel, pero su madre doña Luisa la vigila de cerca. Una noche después de convenirlo por carta, don Pablo se encuentra con la joven y quiere llevarla en un carruaje, cuando doña Luisa "juzgando, con razốn, que no iba a misa // ...entre los dos, de sopetón, plantóse." La acción termina con que "Isabel en coche fue llevada // a un monasterio" donde su tía era prelada $\mathrm{y}$

Tomó por nombre Sor Escutafina de la Circuncisión: inombre elegante! y la nombró portera la prelada porque la vio al zaguán aficionada.

Sabemos luego que el enamorado se encuentra encerrado en otro convento de hombres, donde compone las ya referidas líneas sobre los derechos individuales. Mueren los padres de los dos y por fin el amante; al hacer éste su confesión, i recibe confidencias de boca del confesor que nos sugieren que éste era el padre del moribundo! Esto sucede durante el terremoto de julio de 1773 , en el cual perdió la vida don Pablo. El cuento

esta antología ofrece también una buena selección de otras poesias, y una introducción en la cual Uriarte dice que Batres cantó lo que sentia.

5 "El modelo no implica servidumbre para Batres" dice Julio A. Leguizanón en su Historia de la literatura bispanoamericana, I, 402 (Buenos Aires, 1945), 2 tomos. 
es sencillo, pero el autor supo entretener al lector con frases graciosas, versificación desenvuelta, amonestaciones a doncellas castas, y digresiones al estilo de Byron. Pepe demuestra su humorismo cuando explica la muerte de los padres, uno de haber ido con catarro a la iglesia, otro por andar por la casa sin camisa, y doña Luisa peleando con los miembros de su familia.

Las falsas apariencias es otra historieta que narra cómo quedó cojo don Juan del Puente. El protagonista, quien vivía del negocio perfectamente respetable de contrabandista de sedas, tabaco y ron, volvió a casa una noche para encontrar a un extraño en el lecho conyugal:

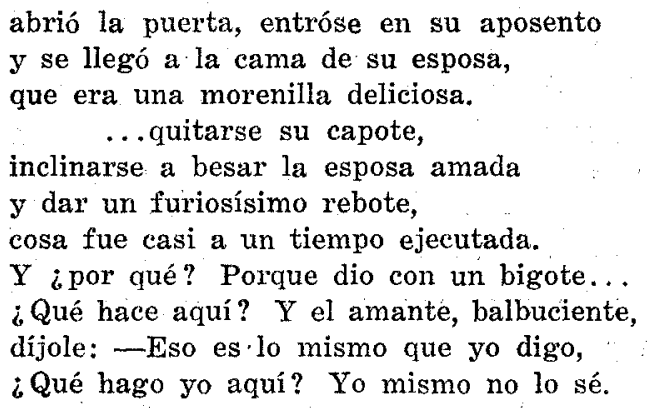

Los dos culpables afirman su inocencia, pero don Juan empieza la pelea, recibiendo una herida en la pierna que lo deja cojo. Este viejísimo triángulo vive por la gracia de sus versos; unas líneas omitidas en las primeras ediciones demuestran admirablemente la soltura de Pepe Batres aun describiendo los asuntos más delicados:

Ella, entre tanto, alzábașe del lecho, lánguido el rostro, sueltos los cabellos, mal encubierto el palpitante pecho, bien dibujados los contornos bellos.

El poeta estaba componiendo otro cuento en verso titulado El relox cuando lo llamó la muerte; la desgraciada casualidad de dejarlo sin terminar ha servido de acicate a muchos aspirantes poetas de Centroamérica, desde Salvador Barrutia 
en 1881 hasta mi amigo del Palacio.6 Trata de "el primer relox de campanilla // que vino a Guatemala" en la posesión de don Alejo Veraguas de Comayagua; a continuación leemos su retrato:

$$
\begin{aligned}
& \text { en su modo de hablar era europeo, } \\
& \text { y además, tan galán, tan currutaco, } \\
& \text { que nadie le igualaba en un paseo. } \\
& \text { A la verdad, era un poquillo flaco, } \\
& \text { y visto de perfil era algo feo, } \\
& \text { y algo pecoso, y le faltaba un diente, } \\
& \text { mas era muy buen mozo, muy decente. }
\end{aligned}
$$

Nos recuerda a otro hondureño retratado por José Milla, el divertidísimo capitán Ballina de Las memorias de un abogado; como el capitán, don Alejo:
Por la menor cuestión sacaba el sable, y siempre se metía hasta los codos en negocios de intrigas y de amores, de los cuales contaban mil horrores.

Los vecinos, y sobre todo las vecinas, lo admiraban, pero con una admiración al través de la ironía de nuestro Pepe:

- Allá viene! iAllá viene! ¡Qué galån!

Don Alejo es aquel que se adelanta!

¡Allá viene montado en su alazán!

¡Qué planta de animal! ¡qué hermosa planta!

La escena en el dormitorio es igualmente divertida, con" "el amante escuchando desde el suelo, // entre su vencedora y la pared" hasta que suena el reloj, ya tan conocido en la ciudad.

A causa de sus frecuentes visitas a casa de doña Clara ("era ún almíbar doña Clara" exclama el poeta), los chismes han corrido por la ciudad ("El que dice vecinas dice espías... la vecinal ponzoña" observa Pepe, casi como si fuera una queja personal), y a "la mañana siguiente icosa rara // todo el mun-

6 Rigoberto Bran Azmitia, "Continuación de El relax" en las páginas 5 y 6 del periódico Evolución, Guatemala, 11 de julio de 1945. 
do sabía la aventura" de modo que los vecinos acuden con sus comentarios y consejos:

$$
\begin{aligned}
& \text { Digo, ¿qué significa ese chinchón } \\
& \text { que veo que le asoma por la sien? } \\
& \text { ¿Es cierto que asustaron a madama } \\
& \text { ciertos ruidos debajo de la cama? }
\end{aligned}
$$

El marido acaba imponiendo rigurosas condiciones que dejan a la esposa casi prisionera en su casa. Un día, después de previo permiso, logra visitar a una amiga, y el cuento termina con un lamento de parte de don Alejo, quien llega para requebrarla.

El profesor Alfred Coester en A Literary History of Spanish America7 califica las Tradiciones de "three bits of scandal that might be localized anywhere", pero soy de otro parecer: describen a Guatemala con sus chismes, beatas y enamorados de la época de Pepe, del tiempo de la colonia, y de hoy en día. Don Pablo asistió al Colegio Tridentino, por ejemplo, donde Pepe dictó una conferencia, y don Cornelio vivía de una plantación de caña de azúcar como muchos finqueros ahora. La capital era muy provinciana, como lo sigue siendo todavía. Su manera de redactar estas costumbres es personalísima, graciosa y sumamente divertida, debida a su originalidad y a la elegancia pulida de su verso. Boris de Tannenberg en La poésie contemporaine, Espagne et Améri$q u e^{8}$ dijo que Batres era un artista en sus cuentos, y es verdad: Pepe puede llegar hasta la licencia, pero no a la obscenidad de su modelo italiano, porque salva la narración por "lo cómico del carácter". Menéndez y Pelayo en su Antología de poetas hispanoamericanos dice:9

$\mathrm{Y}$ el chiste no depende aqui de la vil lascivia que nunca puede ser fuente de placer intelectual y desinteresado, sino de la virtud purificada del donaire $y$ del prestigio elegantísimo de

7 (New York, 1916), págs. 446-7.

8 (París, 1889), pág. 281.

9 I. clxxiii (Madrid, 1927-28, 4 tomos). El polígrafo español discurre sobre el poeta en las páginas clxii à clxvii de este tomo, y ofrece $E l$ velox y $Y o$ pienso en ti (p. 300 para éste, y págs. 232-360 para aquél). 
la forma, la cual tiene por sí misma tal vez, que anula y destruye el prosaico y vulgar contenido, y deja campear libre y sola la graciosa fantasía del poeta, a quien no se puede menos de admirar, lamentando al propio tiempo que malgastase tan opulenta vena cómica en tan vil materia.

Pedro Henríquez Ureña dice que descubrió un nuevo campo de exploración en el cuento en verso, y que lo siguió con éxito y afán. ${ }^{10}$

Las Tradiciones revelan muchas ideas del poeta, sobre todo en los apartes byronescos; aquí se vislumbra su gran cariño por Guatemala y las cosas chapinas, a pesar del profundo desengaño que le causaron las pasiones políticas de sus compatriotas. Estaba al tanto de las noticias mundiales a pesar del aislamiento de Guatemala, y lo demuestra en El relox cuando habla:

del precio del cacao en las Antillas, de las noticias últimas de España y del conflicto con la Gran Bretaña.

Pepe Batres se aprovechaba de una situación para describirla irónicamente, de otra para ensalzar las virtudes de la patria, y a veces quiere filosofar, como en estas líneas de Las falsas apariencias:
El nombre de la patria me enardece porque la adoro, estando persuadido de ser ella quien menos lo merece de cuantas patrias hay, habrá o ha habido. Mas como otra no tengo, me parece que debe amarla como el ave al nido, y a los diablos me doy si considero que la quieren vender al extranjero.

Pepe nunca se destacó como político y esta desesperación dio a su voz el tono quejumbroso del patriota desengañado; calificó a la política como "fiebres" y se rio del proyecto de poner lagartos y colmenas en el escudo guatemalteco durante ia asamblea constituyente de los años 1842 y 1843. Estas ideas no le inspixaron simpatía hacia el general y presidente liberal,

10 Las corriente literarias en la América bispánica (México, 1949), pág. 113. 
Morazán; pero tampoco la sintió por el mozo ladino que lo venció, Rafael Carrera, a quien llamó bribón y "bandolero".

José Batres Montúfar murió soltero $-\mathrm{y}$ posiblemente suicida- el 10 de julio de 1844, a la edad de treinticinco años. Había ingerido mucho sulfato de quinina y tuvo el bazo hinchado por las complicaciones palúdicas, de modo que se explica su muerte temprana. Sus amistades, a quienes encantaba su gracia y que gozaban de su compañía, quedaron dolorosamente sorprendidos de su muerte. Aparentemente, no tuvo en sus últimos días motivo de excesiva tristeza, pues ya había pasado sus peores años, y con el partido conservador en el poder, los Batres recibian su protección; pero es casi seguro que las penas sufridas en la juventud dejaron una huella que amargó la vida del poeta, pues expresó el deseo de morir en una carta a su hermana Nela. En su ensayo sobre Guatemala, José Martí cita a Dionisio Alcalá Galiano: "Harta enfermedad tenía él con vivir".11 José Batres dedicó El relox al literato español cuando éste vivía en el Istmo; más tarde sirvió como director de El Diario de la Marina de la Habana, donde Martí lo conocería. Como Martí había tratado a muchos amigos del poeta en Guatemala y en Cuba, su juicio puede ser considerado casi contemporáneo.

Nuestros informes acerca del poeta nos revelan al típico criollo en su desidia y su propensión a soñar; en muchos sentidos era un constante inadaptado porque todo lo que abarcó salió mal excepto su poesía. Dice en su dedicatoria de El relox que no comenzó a escribir con la intención de ser poeta, pero al leer cualquier verso de Batres Montúfar, se sabe a quién atribuirlo; el estilo de Pepe es inequívoco, y sentimos que debemos llamarle por el diminutivo. Otra cosa digna de notarse en sus obras es el formal pulimiento del clasicismo; aunque creció en pleno período romántico, no era un romántico a la

11 Martí publicó su ensayo por primera vez en México en 1877; cito la reciente edición del Ministerio de Fducación Pública (Guatemala, 1953). Arzú atribuye esta observación al artista español Francisco Pineda en la página 120 de Pepe Batres intimo. 
francesa. Su humorismo ha sido ampliamente comentado por los críticos y hay poco que se le pueda agregar a estos encomios; sus penas físicas y espirituales no le impidieron describir alegremente el paisaje, habitantes y costumbres de su patria, con las guarniciones de los caballos, las fiestas y ceremonias, y las cartas de los enamorados. Como Fígaro, encontró el lado flaco del prójimo, y con este talento algo pícaro sazona sus escritos. Podía pasar de la ironía más terrible a la cortesía cumplida, de la calma a la tempestad, según Moncada. ${ }^{12}$

Pepe Batres tuvo la complexión clara, el cabello castaño, la nariz encorvada y los ojos oscuros y penetrantes. La cabeza era grande, la frente alta y despejada, las cejas pobladas y los pómulos salientes. Tenía un bigote escaso, una barba bien arreglada, el cuello bien proporcionado, y las espaldas fuertes. Lo demás de su cuerpo parecía endeble y nervioso, y sus sensaciones pasaban fácilmente al cerebro o al corazón. Tenía cinco pies cuatro pulgadas de alto $(160 \mathrm{~cm}$.) según su certificación militar; en esto fue típicamente chapín, porque en su estatura muchos guatemaltecos siguen a la pequeñez física de los mayas. Creía que tenía la nariz tan "desaforada" que la gente se burlaba de él; no obstante, una de sus estudiantes de guitarra afirmó que no era feo y que el poeta exageraba sus defectos. 13

Los funerales se celebraron en San Juan de Dios, probablemente al día siguiente de su fallecimiento. Un "extranjero" mandó publicar la noticia en la Gaceta Oficial diez días más tarde, con un resumen de la vida del poeta, donde dijo que vivía muy apartado de la vida. Tenemos una conferencia suya destinada al Colegio Tridentino, la que Pepe Milla tuvo que leer, sea porque no le gustase a Batres aparecer ante un

12 Citada en la edición de 1944 (Guatemala, Sociedad de Geografía e Historia, 1944), pág. 230.

13 José Arzú nos ofrece un retrato del poeta en la página 50 de Pepe Batres intimo hecho por el pintor Humberto Garavito, el que es reproducido en la portada de la última edición de sus poesías publicada por el Ministerio de Educación Pública (Guatemala, 1952). También hay un sello postal de tres centavos con el perfil del poeta. Los retrateos póstumos se basan en su máscara mortuoria, conservada por la familia hasta la fecha. 
público, o sea porque ya no se sintiera con fuerzas para hacerlo. 14 Se celebró un acto en la Universidad de San Carlos recientemente restablecida, y un grupo literario que incluía al difunto celebró una velada para conmemorar al miembro ausente.

Cuando se sugirió allí que el poeta sería pronto olvidado, un joven amigo, José Milla y Vidaurre, resolvió recoger sus poesías y publicarlas; así el otro Pepe guatemalteco arregló los manuscritos entregados por la familia.15 Esta edición primitiva costaba tres reales si era pagada con anticipación, o cuatro una vez aparecido el tomo; salió el 20 de septiembre de 1845 con una introducción cuya mayor parte trata de las obras del poeta y muy poco de su vida. Desde esa fecha han sido impresas casi una docena de ediciones, entre ellas la del año 1882 por la editorial parisina de Garnier Frères, otra por $E l$ Globo de Guayaquil cinco años más tarde, y una en Madrid por la prensa Helénica en 1924; todas las demás han sido guatemaltecas. 16

Juan Valera lo apreció, y don Marcelino lo colocó entre los románticos como Heredia, Bello y Olmedo; en su 'Antología ya citada, lo llama "la verdadera gloria poética de Guatemala".17 Solo Clarín, entre los críticos peninsulares, no llevó buena impresión de su poesía; rechazó al Batres presentado por Tannenberg, y éste era un Pepe truncado. En su libro Ensayos y revistas, 1888-1892,18 Leopoldo Alas dice: "Ese Sr. Batres, poeta americano que a él tanto le gusta, hacía muy medianos versos"; copia dos estrofas de Las falsas apariencias fuera de su contexto y dice que son pésimas. Clarín no puede

14 Esta conferencia se encuentra en las páginas $261-6$ de Arzú. El extranjero fue Alcalá Galiano, según dicen.

15 Véase la introducción de F. Hernández de León a su edición de El visitador por José Milla (Guatemala, 1935).

10 Estos datos pueden confirmarse en la página 197 de la edición de sus Poesías publicada por la Sociedad de Geografía e Historia en el centenario de su muerte. Lleva un prefacio de Carlos Gándara Durán y juicios de críticos peninsulares y continentales en las págs. 201 y 356.

17. Op. cit., I. clxii.

18 (Madrid, 1892), pág. 237. Hizo otro juicio sumario inmediatamente des. pués sobre el colombiano Gregorio Gutiérrez y González, autor de la memoria sobre el maíz. 
ver el chiste, sencillamente; es evidente que no ha leído más que esos versos, y que no conoce el ambiente del cual se burla el guatemalteco. Más fidedigno es el criterio que hizo Rubén Darío del poeta chapín; hablando de $E l$ relox y de Las falsas apariencias, dice: "son estos dos poemitas dos joyeles de la literatura americana," 19 y compara al guatemalteco a un prestidigitador con naipes o cuchillos en sus rimas acertadas y sus chistes afilados. El nicaragüiense corrobora su opinión sobre la sociedad guatemalteca, que conoció personalmente, y esto es más importante que la crítica de un escritor europeo que nunca visitó nuestro continente.

Se puede decir que Pepe Batres no fue comprendido; pasó su corta vida en un ambiente revuelto, y rodeado de amigos y vecinos con poca comprensión de su genio y amplia cultura. En el fondo de sus obras, escondida entre sus estrofas acerbas y sus púas tan acertadas, podemos inferir una tristeza, esa molestia de poseer un alma exquisita y a la vez tener que vivir en un aislamiento artístico. Su reserva tan estudiada y su sátira forman una mezcla de rebelión sofocada y de protesta abierta. Su belleza estilística es una obra única, su fantasía una evasión de la realidad, y su predilección por las tradiciones coloniales una huida de las verdaderas molestias de su época. En suma, Pepe Batres fue un gran poeta, un gran romántico y un gran americano. Más que todo, si la gente sigue aprendiendo sus versos de memoria más de cien años después de su muerte, esto nos da la máxima prueba del verdadero poeta.

Thomas B. Inving, Universidad de Minnesota.

19 Pág. 190 de su ensayo "La literatura en Centro América", reproducido en las págs. 186-212 de Obras desconocidas, ed. Raúl Silva Castro (Santiago, 1934). 
